\title{
Factors determining successful computed tomography-guided localization of lung nodules
}

\author{
Jung Min Seo, MD, ${ }^{a}$ Ho Yun Lee, MD, ${ }^{a}$ Hong Kwan Kim, MD, PhD, ${ }^{\mathrm{b}}$ Yong Soo Choi, MD, PhD, \\ Jhingook Kim, MD, PhD, ${ }^{\mathrm{b}}$ Young Mog Shim, MD, PhD, ${ }^{\mathrm{b}}$ and Kyung Soo Lee, MD, PhD ${ }^{\mathrm{a}}$
}

Objectives: To investigate the factors related to the successful computed tomography-guided nodule localization for subsequent nodule excision.

\begin{abstract}
Methods: We retrospectively reviewed the medical records for 181 patients who had undergone computed tomography-guided nodule localization using hook wire and subsequent video-assisted thoracic surgery resection for lung nodules. The demographic factors, nodule factors, and technical factors were reviewed to determine what affects effective nodule localization for video-assisted thoracic surgery resection using both univariate and multivariate models.
\end{abstract}

Results: A total of 174 patients were included in our study. Successful localization was accomplished in 166 patients $(95 \%)$. Univariate analysis implicated patient age, nodule solidity, zonal location, and a sufficient distance between the hook wire tip and pleural surface as significant factors for successful localization. Multivariate analysis focused on the distance between the wire tip and pleural surface as the sole independent factor for successful localization $(P=.012)$.

Conclusions: The distance between the hook wire tip and pleural surface was the major significant factor for successful computed tomography-guided nodule localization for subsequent video-assisted thoracic surgery resection. Thus, the localization of a hook wire adjacent to a target nodule with sufficient depth from the pleural surface is crucial to the success of the procedure. (J Thorac Cardiovasc Surg 2012;143:809-14)

Lung cancer is the most common cause of cancer death for both men and women in developed countries. ${ }^{1}$ The overall 5 -year survival rate of lung cancer is only $15 \%$. However, the 5-year survival rates can reach $\leq 60-80 \%$ when lung cancer is detected at an early stage (eg, at stage I when the tumor dimension is $\leq 3 \mathrm{~cm}$ in diameter). ${ }^{2,3}$ Thus, early detection is the only method of increasing patient survival in lung cancer.

With the application of computed tomography (CT) imaging techniques to lung cancer screening, small subcentimeter lung nodules are frequently detected..$^{4-7}$ However, at the moment, it is difficult to characterize subcentimeter lung nodules with noninvasive imaging techniques alone ${ }^{6,8}$ Furthermore, the detection of groundglass opacity nodules (GGNs), known to exhibit high

\footnotetext{
From the Department of Radiology and Center for Imaging Science ${ }^{\mathrm{a}}$ and Department of Thoracic and Cardiovascular Surgery, ${ }^{\mathrm{b}}$ Samsung Medical Center, Sungkyunkwan University School of Medicine, Seoul, Korea.

Disclosures: Authors have nothing to disclose with regard to commercial support.

Received for publication July 18, 2011; revisions received Sept 16, 2011; accepted for publication Oct 20, 2011; available ahead of print Nov 21, 2011.

Address for reprints: Ho Yun Lee, MD, Department of Radiology, Samsung Medical Center, Sungkyunkwan University School of Medicine, 50, Ilwon-Dong, Kangnam-Ku, Seoul 135-710, Korea (E-mail: hoyunlee96@gmail.com); or Hong Kwan Kim, MD, PhD, Department of Thoracic and Cardiovascular Surgery, Samsung Medical Center, Sungkyunkwan University School of Medicine, 50, Ilwon-Dong, Kangnam-Ku, Seoul 135-710, Korea (E-mail: hkts@skku.edu). $0022-5223 / \$ 36.00$

Copyright (c) 2012 by The American Association for Thoracic Surgery doi:10.1016/j.jtcvs.2011.10.038
}

malignancy potential, has increased, posing an additional burden on clinicians for tissue confirmation. ${ }^{9}$

The other condition necessitating tissue confirmation is the presence of small lung nodules in a patient with a known extrathoracic malignancy. Small lung nodules in patients with such a malignancy need tissue confirmation for additional treatment planning. A significant improvement in survival rates has been reported after resection of metastatic lung nodules from certain types of extrathoracic malignancies such as colorectal cancer or renal cell carcinoma. ${ }^{10-12}$ Thus, it is expected that cases necessitating surgical tissue confirmation for lung nodules will increase in number.

Because fine needle aspiration or transbronchial biopsy for small lung nodules is difficult and often leads to sampling errors, excisional biopsy using video-assisted thoracoscopic surgery (VATS) is often performed. The VATS procedure has been known to be ideal for nodule resection, because it results in minimal lung volume loss and little postoperative morbidity and mortality. ${ }^{3,13,14}$ However, for GGNs of substantial size or small nodules located in the deep lung parenchyma, localizing them visually or even by palpation during VATS is difficult. ${ }^{15,16}$ Inadequate nodule localization might lead to a prolonged operative time because of a nodule search or conversion to an unplanned open thoracotomy. ${ }^{13,15,16}$ Preoperative localization techniques have been introduced as a method of improving the success rates of VATS and to prevent 


\section{Abbreviations and Acronyms \\ $\mathrm{CT}=$ computed tomography \\ GGN $=$ ground-glass opacity nodule \\ VATS $=$ video-assisted thoracoscopic surgery}

unwanted thoracotomy. ${ }^{15,16}$ To accomplish successful VATS nodule resection, various factors (eg, nodule-related factors on the CT scans, patient demographics, or procedure-related factors) might be related. However, few studies have presented empirical evidence of the factors necessary for success in nodule localization. ${ }^{17}$ Thus, the purpose of our study was to investigate the factors related to successful CT nodule localization for subsequent VATS lung nodule excision.

\section{MATERIALS AND METHODS}

Our institutional review board approved the present retrospective study and waived the requirement for informed consent for the use of medical data from all the patients.

\section{Patients}

From August 2003 through February 2010, a total of 181 patents underwent CT-guided nodule localization by hook wire and subsequent VATS resection for lung nodules detected on chest CT scans. In our institute, preoperative nodule localization was performed for patients with the following criteria: patients without extrathoracic malignancy (those with a suspected primary lung lesion) and nodules less than $3 \mathrm{~cm}$ that were persistent or growing on the follow-up CT images, and patients with an extrathoracic malignancy and any lung nodules less than $3 \mathrm{~cm}$ that had newly appeared on follow-up CT images or persistent or growing lesions. The exclusion criteria were as follows: unavailability of preoperative CT images or the images during nodule localization, the use of a device other than the hook wire for nodule localization, the use of multiple hook wires for the localization of a single nodule, and the absence of VATS resection. For these patients, the demographic information, including the age and gender of patients, and the medical history of having an extrathoracic malignancy were recorded.

\section{CT-Guided Localization}

In a $\mathrm{CT}$ room, the chest $\mathrm{CT}$ scans were taken before the localization procedure to formulate an entire plan for the procedure. The CT scan covered a range limited to the area in which a target nodule could be visualized. The scans were obtained using a 4-slice multidetector CT scanner (LightSpeed QX/i; GE Healthcare, Waukesha, Wis) or a 16-slice multidetector (LightSpeed Ultra or Ultra16, GE Healthcare; or Aquilion, Toshiba Medical Systems, Tustin, Calif). The scan parameters were as follows: $125 \mathrm{~mA}, 120$ $\mathrm{kVp}$, beam width of 10 to $20 \mathrm{~mm}$, and beam pitch of 1.375 to 1.5 . The scan data were reformatted with a $2.0-, 2.5-$, or $5.0-\mathrm{mm}$ section thickness for the transverse images.

A 10-cm-long, 21-gauge-needle/wire and breast lesion localization system (Homer Mammlok Plus; Mitek Surgical Products, Inc, Glen Falls, NY) was used for nodule localization. The needle/wire was inserted into the lung using a percutaneous route. Under CT guidance, the wire was advanced toward the lung parenchyma just lateral to the nodule. Immediate postprocedural CT scans were obtained to assess the relative location of the wire tip to the target nodule and to the pleural surface and to assess the presence of possible complications such as hemorrhage, pneumothorax, or subcutaneous emphysema.

\section{VATS Procedure}

After moving to an operation room, each patient was intubated with a double lumen endobronchial tube to achieve single-lung ventilation during general anesthesia. The patients were positioned in either the left or right lateral decubitus depending on the nodule location. Skin preparation and draping were done. In most patients, 3 VATS trocars (Cabot Medical Corp, Langhorne, Pa) were inserted at the anterior, middle, and posterior axillary lines or subscapular points at a level between the fourth and eighth intercostal space with a minimal skin incision. A $10-\mathrm{mm}, 30^{\circ}$ videotelescope (Karl Storz, Tuttlingen, Germany) was inserted to explore the pleural cavity. Two other ports were used for an endoscopic grasper and endoscopic stapling device. If nodule localization with a hook wire was confirmed by the thoracic surgeon, wedge resection with a sufficient resection margin was performed using several staplers (Multifire EndoGIA 30; Auto Suture, US Surgical Corp, Norwalk, Conn). If the wire was not identified or a nodule was not visualized or palpated, blind wedge resection, considering the location of a nodule on the CT scans, was conducted in the VATS procedure. The thoracic surgeon confirmed that each wire was removed from the pleural cavity, along with the surgical specimens. All resected specimens were sent for immediate histopathologic examination. If a nodule was confirmed to be primary lung cancer by histopathologic examination, additional lobectomy and mediastinal lymph node dissection were performed.

\section{CT Analysis}

The analyzed factors are schematically presented in Figures 1 and 2. The preoperative CT images were reviewed by 2 thoracic radiologists who had chest imaging interpretation experience of 3 and 8 years, respectively. The location and characteristics of each nodule were recorded. The nodule location was subclassified into 3 different lung zones: upper (right upper lobe and left upper lobe, other than lingular division), middle (right middle lobe and lingular division of the left upper lobe), and lower (right lower lobe and left lower lobe) lung zones. The characteristics (solidity) of a nodule were subclassified into GGNs or solid nodules. The maximum diameter of the nodule, distance from the nodule to the pleural surface, angle between the hook wire and the pleural surface (in degrees), distance between the wire tip and the pleural surface (in millimeters), and wire depth within the thoracic wall (in millimeters) were measured using electronic calipers on the picture archiving and communication system (Centricity, GE Healthcare) and recorded.

\section{Statistical Analysis}

Wire localization was considered technically successful when the wire could be identified visually by a surgeon during the VATS resection procedure. Specifically, if the surgeon identified a localized needle in the segment of the lesion that correlated with the postprocedural CT scans, we considered it a technical success. The nodule factors evaluated included nodule size (maximum diameter), zone location, nodule solidity, and distance from a nodule to the pleural surface. The technical factors evaluated were the angle between the nodule and the pleural surface, distance between the wire tip and pleural surface (in millimeters), and wire depth within the thoracic wall (in millimeters).

The descriptive analysis results are expressed in terms of the frequency, mean, and standard error. Frequencies were compared using Fisher's exact test for categorical variables to compare the differences between the success and failure groups for nodule localization. The Mann-Whitney $U$ test was used to compare continuous variables. Linear regression analysis was performed for multivariate analysis. Statistical analysis was performed using the Statistical Package for Social Sciences, version 15, statistical software for Windows (SPSS, Chicago, Ill). The values are expressed as the mean \pm standard deviation. $P \leq .05$ was considered statistically significant. 


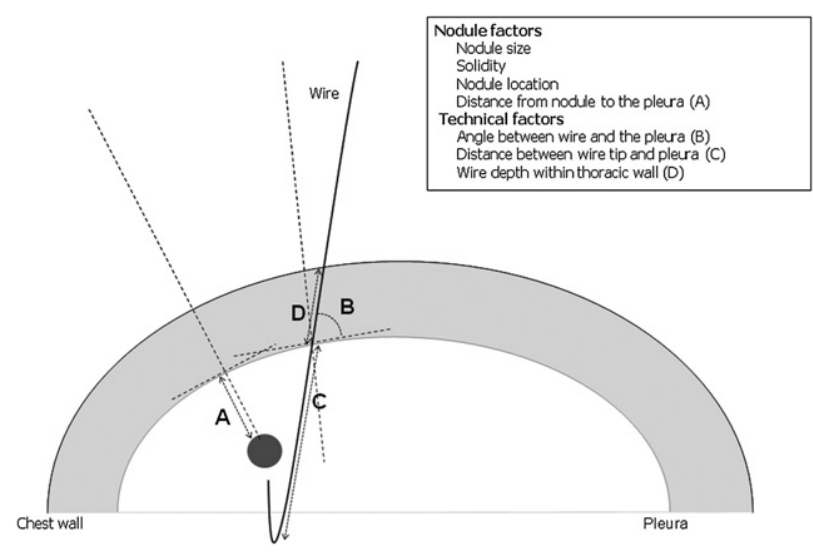

FIGURE 1. Intrinsic and technical factors analyzed to determine which were related to successful computed tomography $(C T)$-guided nodule localization.

\section{RESULTS \\ Patients}

Of 181 patients, 7 were excluded because of the following reasons: $\mathrm{CT}$ scans obtained during wire localization could not be viewed using the picture archiving and communication systems in 1 patient; methylene blue was used for localization in 2 patients; 2 wires were used for 1 nodule localization in 1 patient; and localization was performed but the surgery was not conducted in 3 patients. Thus, 174 patients $(83$ men and 91 women; age range, 14 to 85 years; mean, 56) were included in the present

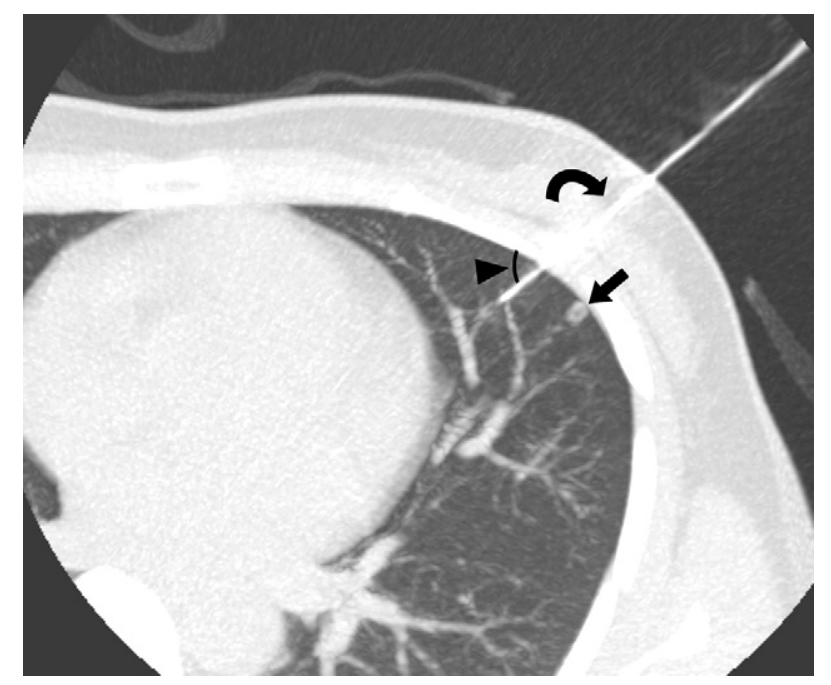

FIGURE 2. Computed tomography $(C T)$-guided nodule localization with hook wire performed for 4-mm subpleural nodule (arrow) in lingular division of left upper lobe of 47-year-old woman with history of cervical cancer. Preoperative CT diagnosis for ground-glass opacity nodule $(G G N)$ was metastasis. Angle (arrowhead) between wire and pleural surface was $67^{\circ}$, and the wire (curved arrow) was stably located next to nodule with sufficient distance between wire tip and pleural surface (14 $\mathrm{mm}$ in length on CT scan). Video-assisted thoracoscopic surgery (VATS) was successful, and pathologic finding was metastasis.
TABLE 1. Patient and nodule characteristics

\begin{tabular}{|c|c|}
\hline Characteristic & Value \\
\hline \multicolumn{2}{|l|}{ Clinical $(\mathrm{n}=174)$} \\
\hline \multicolumn{2}{|l|}{ Gender } \\
\hline Male & 83 \\
\hline Female & 91 \\
\hline Age $(y)$ & $56.2 \pm 10.5$ \\
\hline History of extrathoracic malignancy & 79 \\
\hline \multicolumn{2}{|l|}{ Nodule } \\
\hline Size (mm) & $10.3 \pm 5.2$ \\
\hline \multicolumn{2}{|l|}{ Solidity } \\
\hline GGN & 106:68 \\
\hline \multicolumn{2}{|l|}{ Solid } \\
\hline Nodule to pleural distance (mm) & $10.0 \pm 8.1$ \\
\hline \multicolumn{2}{|l|}{ Nodule location } \\
\hline Upper lobe & 81 \\
\hline Middle lobe & 19 \\
\hline Lower lobe & 74 \\
\hline \multicolumn{2}{|l|}{ Pathologic finding } \\
\hline Malignancy & $108(62)$ \\
\hline Lung adenocarcinoma & $43(25)$ \\
\hline Bronchioloalveolar carcinoma & $35(20)$ \\
\hline Metastasis & $28(16)$ \\
\hline Bronchus-associated lymphoid tissue lymphoma & $1(0.5)$ \\
\hline Atypical carcinoid tumor & $1(0.5)$ \\
\hline Benign & $66(38)$ \\
\hline Anthracofibrotic nodule & $19(11)$ \\
\hline Granuloma & $15(9)$ \\
\hline Intrapulmonary lymph node & $7(4)$ \\
\hline Chondroid hamartoma & $6(3)$ \\
\hline Miscellaneous & $19(11)$ \\
\hline Procedure time (localization to operation) (h) & $5.2 \pm 3.3$ \\
\hline \multicolumn{2}{|l|}{ Surgery } \\
\hline VATS wedge resection & $171(98)$ \\
\hline Conversion to thoracotomy & $3(2)$ \\
\hline Open wedge resection & 1 \\
\hline Lobectomy with mediastinal node dissection & 1 \\
\hline Segmentectomy & 1 \\
\hline
\end{tabular}

Continuous variables presented as mean $\pm \mathrm{SD}$ and categorical variables as numbers (\%). GGN, Ground-glass opacity nodule.

retrospective analysis. Of the 174 patients, 79 had an extrathoracic malignancy, in addition to indeterminate nodules. The demographic information is listed in Table 1. Three patients underwent thoracotomy because of a bleeding tendency due to bronchiectasis in 1, a deep location and movability of the nodule in 1 , and a pleural adhesion in 1 patient. Their eventual operations are described in Table 1. The successful placement of wires and stable location were identified on VATS exploration in 166 patients (technical success rate, $95 \%$ ). Wire dislodgement between the radiology suite and operation room was found in all 8 failure cases.

On the postprocedural CT scans, pneumothorax was observed in 69 patients $(40 \%)$. Lung parenchymal hemorrhage was exhibited in 62 patients ( $36 \%$ ), and subcutaneous emphysema was noted in 8 patients $(5 \%)$. One patient 
TABLE 2. Univariate analysis results

\begin{tabular}{|c|c|c|c|}
\hline Characteristic & $\begin{array}{l}\text { Success group } \\
\quad(\mathbf{n}=\mathbf{1 6 6})\end{array}$ & $\begin{array}{l}\text { Failure group } \\
\quad(\mathbf{n}=\mathbf{8})\end{array}$ & $\begin{array}{c}P \\
\text { value }\end{array}$ \\
\hline \multicolumn{4}{|l|}{ Demographic factors } \\
\hline Age (y) & $56.5 \pm 10.4$ & $49.4 \pm 10.5$ & .07 \\
\hline Gender & & & .56 \\
\hline Male & $80(48.2)$ & $3(37.5)$ & \\
\hline Female & $86(51.8)$ & $5(62.5)$ & \\
\hline \multicolumn{4}{|l|}{ Pulmonary function } \\
\hline FVC $(\%$ predicted $)$ & $97.0 \pm 18.2$ & $101.3 \pm 20.0$ & .09 \\
\hline $\mathrm{FEV}_{1}(\%$ predicted $)$ & $83.2 \pm 17.5$ & $84.7 \pm 19.4$ & .86 \\
\hline \multicolumn{4}{|l|}{ Nodule factors } \\
\hline Nodule size & $10.3 \pm 5.3$ & $9.3 \pm 3.1$ & .74 \\
\hline Solidity & & & .04 \\
\hline GGN & 33 (19.9) & $4(50)$ & \\
\hline Solid & $133(80.1)$ & $4(50)$ & \\
\hline Location & & & .04 \\
\hline Upper & $80(48.2)$ & $1(12.5)$ & \\
\hline Middle & $18(10.8)$ & $1(12.5)$ & \\
\hline Lower & $68(41.0)$ & $6(75.0)$ & \\
\hline $\begin{array}{l}\text { Distance from nodule to } \\
\text { the pleura }\end{array}$ & $10.0 \pm 8.1$ & $7.4 \pm 9.3$ & .20 \\
\hline Pathologic finding & & & .97 \\
\hline Benign & $61(36.7)$ & $3(37.5)$ & \\
\hline Malignant & $105(63.3)$ & $5(62.5)$ & \\
\hline \multicolumn{4}{|l|}{ Technical factors } \\
\hline $\begin{array}{l}\text { Angle between wire and } \\
\text { pleura }\end{array}$ & $58.3 \pm 17.4$ & $59.2 \pm 20.6$ & .79 \\
\hline $\begin{array}{l}\text { Distance between wire tip } \\
\text { and pleura }\end{array}$ & $31.2 \pm 16.8$ & $8.3 \pm 5.3$ & $<.00$ \\
\hline $\begin{array}{l}\text { Wire depth within thoracic } \\
\text { wall }\end{array}$ & $37.4 \pm 11.2$ & $34.6 \pm 9.6$ & .80 \\
\hline
\end{tabular}

$\overline{\text { Continuous variables presented as mean } \pm \mathrm{SD} \text { and categorical variables as numbers }}$ (\%). $F V C$, Functional vital capacity; $F E V_{l}$, forced expiratory volume in 1 second; $G G N$, ground-glass opacity nodule.

experienced an event of vasovagal syncope after the wire localization procedure. None required specific intervention for wire localization-associated complications.

\section{Factors for Successful Localization}

Of the nodule and demographic factors, patient gender, nodule size, and distance from a nodule to the pleural surface were not related to successful nodule localization on univariate analysis. Patient age, nodule solidity, and zone location were implicated as significant factors for successful localization (Table 2). GGNs were associated with a greater failure rate $(11 \%)$ for localization than the solid nodules (failure rate, $3 \%$ ). The nodules in the lower lung zone have a greater failure rate $(8 \%)$ compared with those in the upper $(1 \%)$ or middle $(5 \%)$ lung zones $(P=.040)$. Regarding the technical factors, the distance between the wire tip and pleural surface was a significant factor $(P<.001)$ in successful localization. The mean distance between the wire tip and pleural surface was $31.2 \mathrm{~mm}$ in the successful group but was $8.3 \mathrm{~mm}$ in the failure group. The angle between the
TABLE 3. Multivariate analysis results

\begin{tabular}{lccl}
\hline \multicolumn{1}{c}{ Variable } & $\boldsymbol{P}$ value & OR & \multicolumn{1}{c}{$\mathbf{9 5} \% \mathbf{C I}$} \\
\hline Age & .28 & 1.085 & $0.937-1.258$ \\
Gender & .09 & 0.042 & $0.001-1.591$ \\
Solidity & .07 & 25.75 & $0.746-888.477$ \\
$\quad \begin{array}{l}\text { Location } \\
\text { Mean distance from nodule to } \\
\quad \text { pleura }\end{array}$ & .16 & 0.143 & $0.010-2.105$ \\
$\quad \begin{array}{l}\text { Mean angle between wire and } \\
\quad \text { pleura }\end{array}$ & .45 & 0.9 & $0.738-1.097$ \\
$\begin{array}{l}\text { Mean distance between wire } \\
\quad \text { tip and pleura }\end{array}$ & .01 & 1.028 & $0.956-1.107$ \\
$\quad \begin{array}{l}\text { Mean wire depth within } \\
\quad \text { thoracic wall }\end{array}$ & .39 & 0.929 & $0.784-1.100$ \\
$\begin{array}{l}\text { OR } \text {, Odds ratio; } C I \text {, confidence interval. } \\
\end{array}$ & & & \\
\end{tabular}

wire and pleural surface or wire depth within the thoracic wall was not a significant factor for successful localization.

When we evaluated all the significant factors (including the demographic, nodule-related, and technical factors that proved to be associated with successful wire localization on univariate analysis) together, the distance between the wire tip and pleural surface (odds ratio, $1.467 ; 95 \%$ confidence interval, 1.086 to $1.980, P=.012$ ) appeared to be the only independent factor for successful localization on multivariate analysis (Table 3 ).

\section{DISCUSSION}

The summary of our study results is as follows. The distance between the hook wire tip and pleural surface is an important factor that determines and results in successful wire localization on both univariate and multivariate analysis; and the significant nodule factors were nodule solidity and zonal location, which were related to successful wire localization on univariate analysis.

In our study, the distance between the wire tip and pleural surface correlated well with successful wire localization. In previous studies, shallow insertion of the tip of the cannula for wire anchoring was associated with dislodgement of the wire. ${ }^{18,19}$ The investigators proposed inserting the tip of the cannula to the lung at least $1 \mathrm{~cm}$ beneath the pleural surface. Our results have shown quantitative evidence that a lengthened distance of insertion (ie, the distance between the wire tip and pleural surface) is an important factor in accordance with the speculations from preceding studies.

The localization wire should be placed as deep as possible for the greatest chance of practical success.

The detection rates of GGN have increased owing to the wide use of low-dose lung cancer screening with CT. However, GGNs are not easily identified during VATS procedures, because these nodules are neither visible nor palpable through a thoracoscope. The difficulty in GGN detection during VATS procedure might result in a high dependency on preoperative nodule localization methods such as 
CT-guided localization. ${ }^{18,20,21}$ Although CT-guided localization with a hook wire followed by VATS resection for treating small GGNs is an efficient procedure, the method is associated with a high failure rate compared with localization of solid nodules. Thus, special care should be taken in securing a stable location of a hook wire during and after CT-guided localization with sufficient wire depth in cases of GGNs.

Moreover, the location of a lung nodule is an important intrinsic factor for successful localization. Lung nodules distributed in the lower lobes were associated with a high failure rate compared with those in the upper or middle lobes. Hook wire targeting of the nodules located in the lower lobes is vulnerable to wire dislocation, probably owing to the wide lung excursion during respiration.

Dendo and colleagues ${ }^{18}$ classified the preoperative techniques of pulmonary nodule localization into 3 major types: image-guided surgery, injection of liquid material, and placement of percutaneous wires. Although intraoperative ultrasonography promises safety, it can be time consuming and has difficulty in detecting deeply seated lung nodules or an emphysematous lung. ${ }^{22,23}$ Various liquid materials are used for lung nodule localization such as methylene blue dye,${ }^{24}$ barium, ${ }^{25}$ indio carmine, ${ }^{26}$ and lipiodol..$^{21}$ However, rapid diffusion of these liquids could cause high failure rates. ${ }^{14}$ Unintentional injection of dye or lipiodol into the systemic or pulmonary circulation can cause significant anaphylactoid reactions or embolisms. ${ }^{27}$ The use of hook wires is the oldest and most common technique. ${ }^{28,29}$ Modification of this technique with suture material or other devices has focused on reducing complications resulting from wire rigidity such as wire migration. ${ }^{14,18,30}$

Our study was designed to prove the hypothesis that the 2 following factors help stabilize hook wire localization and lead to the success of subsequent VATS nodule resection: a proper needle path angle for hook wire localization and a sufficient distance between the wire tip and pleural surface. In our study, the angle between the wire path and the pleural surface did not appear to be a significant factor affecting successful localization. Only the distance between the wire tip and pleural surface proved significant. One reasonable explanation for our results is that by sufficiently securing the hook wire depth, the problem with the angle can be compensated for; thus, a proper needle path angle is not necessary. However, a point that must be considered is that 1 of the goals of VATS nodule excision and biopsy is to minimize the loss of the normal lung parenchyma. Thus, inserting a wire at a vertical angle could also be important for achieving a minimal resection volume, although that is not directly related to the success rate of CT-guided localization.

In terms of nodule penetration, previous studies have supposed that penetration of the target nodule was necessary for securing successful localization. ${ }^{14,18,19}$ However, we believe that a wire should be located proximal to the nodule to avoid tumor seeding through the needle track, particularly in situations of multiple needle paths, and to reduce the possibility of impedance of specimen acquisition owing to needle penetration-associated hemorrhage or inflammation within nodule. In our institution, it is common practice to pass the hook wire through the lung parenchyma (after skin and chest wall penetration) on a route away from the target of VATS nodule resection.

Our study had several limitations. First, successful localization during the operation was judged entirely according to the operative record. However, no discrepancy was found between the final CT findings taken after CT-guided localization and the surgical approach recorded in the operative records. The CT images in each step of the localization procedures were well preserved in our picture archiving and communication systems, and the factors associated with wire localization were well recorded in the surgery descriptions. Thus, we presumed that the assessment of both CT imaging findings and surgical records were sufficient for evaluating the factors required for successful wire localization. Second, we could not analyze the relationship between the success of the VATS procedure and the various factors related to wire localization. However, because several compounding factors such as tumor aggressiveness and each surgeon's different VATS technique could have affected the success of the VATS procedure, the relationship between the success of the VATS procedure and CT-guided wire localization could not be easily determined. Moreover, no consensus has been reached among thoracic surgeons as to which issue is related to successful VATS procedure in terms of operative time, resected lung volume, and complication rate. Despite these limitations to our study, we believe that a sufficient length between the tip of a hook wire and pleural surface increases the success in localization of a targeted lung nodule for subsequent VATS lung resection.

\section{CONCLUSIONS}

The distance between the wire tip and pleural surface was the only significant factor for successful CT-guided nodule localization and subsequent VATS nodule resection in our retrospective review. The localization of a hook wire with sufficient depth from the pleural surface leads to increased success of VATS procedures, even if the angle between the needle path and the pleura is neither vertical nor nearly vertical.

\section{References}

1. Jemal A, Murray T, Samuels A, Ghafoor A, Ward E, Thun MJ. Cancer statistics, 2003. CA Cancer J Clin. 2003;53:5-26.

2. Flehinger BJ, Kimmel M, Melamed MR. The effect of surgical treatment on survival from early lung cancer: implications for screening. Chest. 1992;101: 1013-8.

3. Jangra D, Powell T, Kalloger S, Guerra H, Clifton J, Coxson H, et al. CT-directed microcoil localization of small peripheral lung nodules: a feasibility study in pigs. J Invest Surg. 2005;18:265-72. 
4. Henschke CI. Early lung cancer action project: overall design and findings from baseline screening. Cancer. 2000;89:2474-82.

5. Diederich S, Thomas M, Semik M, Lenzen H, Roos N, Weber A, et al. Screening for early lung cancer with low-dose spiral computed tomography: results of annual follow-up examinations in asymptomatic smokers. Eur Radiol. 2004;14: 691-702.

6. Diederich S, Wormanns D, Semik M, Thomas M, Lenzen H, Roos N, et al. Screening for early lung cancer with low-dose spiral CT: prevalence in 817 asymptomatic smokers. Radiology. 2002;222:773-81.

7. Swensen SJ, Jett JR, Sloan JA, Midthun DE, Hartman TE, Sykes AM, et al. Screening for lung cancer with low-dose spiral computed tomography. Am J Respir Crit Care Med. 2002;165:508-13.

8. Saito H, Minamiya Y, Kawai H, Nakagawa T, Ito M, Hosono Y, et al. Usefulness of circumference difference for estimating the likelihood of malignancy in small solitary pulmonary nodules on CT. Lung Cancer. 2007;58:348-54.

9. Nakata M, Saeki H, Takata I, Segawa Y, Mogami H, Mandai K, et al. Focal ground-glass opacity detected by low-dose helical CT. Chest. 2002;121:1464-7.

10. McAfee MK, Allen MS, Trastek VF, Ilstrup DM, Deschamps C, Pairolero PC. Colorectal lung metastases: results of surgical excision. Ann Thorac Surg. 1992;53:780-5.

11. Piltz S, Meimarakis G, Wichmann MW, Hatz R, Schildberg FW, Fuerst H. Longterm results after pulmonary resection of renal cell carcinoma metastases. Ann Thorac Surg. 2002;73:1082-7.

12. Pfannschmidt J, Muley T, Hoffmann H, Dienemann H. Prognostic factors and survival after complete resection of pulmonary metastases from colorectal carcinoma: experiences in 167 patients. J Thorac Cardiovasc Surg. 2003;126: 732-9.

13. Powell T, Jangra D, Clifton J, Lara-Guerra H, Church N, English J, et al. Peripheral lung nodules: fluoroscopically guided video-assisted thoracoscopic resection after computed tomography-guided localization using platinum microcoils. Ann Surg. 2004;240:481-9.

14. Mayo J, Clifton J, Powell T, English J, Evans K, Yee J, et al. Lung nodules: CTguided placement of microcoils to direct video-assisted thoracoscopic surgical resection. Radiology. 2009;250:576-85.

15. Suzuki K, Nagai K, Yoshida J, Ohmatsu H, Takahashi K, Nishimura M, et al. Video-assisted thoracoscopic surgery for small indeterminate pulmonary nodules: indications for preoperative marking. Chest. 1999;115:563-8.

16. Saito H, Minamiya Y, Matsuzaki I, Tozawa K, Taguchi K, Nakagawa T, et al. Indication for preoperative localization of small peripheral pulmonary nodules in thoracoscopic surgery. J Thorac Cardiovasc Surg. 2002;124:1198-202.

17. Nakashima S, Watanabe A, Obama T, Yamada G, Takahashi H, Higami T. Need for preoperative computed tomography-guided localization in video-assisted thoracoscopic surgery pulmonary resections of metastatic pulmonary nodules. Ann Thorac Surg. 2010;89:212-8.

18. Dendo S, Kanazawa S, Ando A, Hyodo T, Kouno Y, Yasui K, et al. Preoperative localization of small pulmonary lesions with a short hook wire and suture system: experience with 168 procedures. Radiology. 2002;225:511-8.

19. Shah RM, Spirn PW, Salazar AM, Steiner RM, Cohn HE, Solit RW, et al. Localization of peripheral pulmonary nodules for thoracoscopic excision: value of CTguided wire placement. AJR Am J Roentgenol. 1993;161:279-83.

20. Tsuchida M, Yamato Y, Aoki T, Watanabe T, Koizumi N, Emura I, et al. CTguided agar marking for localization of nonpalpable peripheral pulmonary lesions. Chest. 1999;116:139-43.

21. Ikeda K, Nomori H, Mori T, Kobayashi H, Iwatani K, Yoshimoto K, et al. Impalpable pulmonary nodules with ground-glass opacity: success for making pathologic sections with preoperative marking by lipiodol. Chest. 2007;131: 502-6.

22. Kondo R, Yoshida K, Hamanaka K, Hashizume M, Ushiyama T, Hyogotani A, et al. Intraoperative ultrasonographic localization of pulmonary ground-glass opacities. J Thorac Cardiovasc Surg. 2009;138:837-42.

23. Greenfield AL, Steiner RM, Liu JB, Cohn HE, Goldberg BB, Rawool NM, et al. Sonographic guidance for the localization of peripheral pulmonary nodules during thoracoscopy. AJR Am J Roentgenol. 1997;168:1057-60.

24. Lenglinger FX, Schwarz CD, Artmann W. Localization of pulmonary nodules before thoracoscopic surgery: value of percutaneous staining with methylene blue. AJR Am J Roentgenol. 1994;163:297-300.

25. Iwasaki Y, Nagata K, Yuba T, Hosogi S, Kohno K, Ohsugi S, et al. Fluoroscopyguided barium marking for localizing small pulmonary lesions before videoassisted thoracic surgery. Respir Med. 2005;99:285-9.

26. Endo M, Kotani Y, Satouchi M, Takada Y, Sakamoto T, Tsubota N, et al. CT fluoroscopy-guided bronchoscopic dye marking for resection of small peripheral pulmonary nodules. Chest. 2004;125:1747-52.

27. Sortini A, Carrella G, Sortini D, Pozza E. Single pulmonary nodules: localization with intrathoracoscopic ultrasound-A prospective study. Eur J Cardiothorac Surg. 2002;22:440-2.

28. Mack MJ, Gordon MJ, Postma TW, Berger MS, Aronoff RJ, Acuff TE, et al. Percutaneous localization of pulmonary nodules for thoracoscopic lung resection. Ann Thorac Surg. 1992;53:1123-4.

29. Plunkett MB, Peterson MS, Landreneau RJ, Ferson PF, Posner MC. Peripheral pulmonary nodules: preoperative percutaneous needle localization with CT guidance. Radiology. 1992;185:274-6.

30. Kanazawa S, Ando A, Yasui K, Tanaka A, Hiraki Y. Localization of small pulmonary nodules for thoracoscopic resection: use of a newly developed hookwire system. Cardiovasc Intervent Radiol. 1995;18:122-4. 